\title{
Government Role in Infrastructure Development in Albania: Efforts for Sustainability
}

\author{
PhD. Fioralba Vela \\ University of Vlora, Albania \\ Email: fiorivela@yahoo.it
}

PhD. Luciana Koprencka

University of Vlora, Albania

Email: lucianakoprencka@yahoo.it

\author{
$\mathrm{PhD}$ candidate. Migena Petanaj \\ University of Vlora, Albania \\ Email: migenapetanaj@hotmail.com
}

\section{Doi:10.5901/mjss.2013.v4n2p361}

\section{Abstract}

This paper mainly focuses on transport development in Albania and policy objectives and decision making in transport infrastructure investments that aims the sustainability of this development and the integration of Albania in the EU. Albania is facing a lot of challenges in developing infrastructure. The challenge of developing transport policies for sustainable development is to orient the sector towards a compromise that maximizes the economic and social benefits of transport and minimizes associated environmental, social and economic costs. Many of the measures required to achieve this balance are not new, the main difficulty is effective implementation. In this paper the author tend to give some important recommendations for strategy design and implementation according to the need of respecting European standards and integration.

Key terms: sustainable, transport development, planning , decision making

\section{Development of transport sector in Albania}

Table. 1 and Figure . 1 shows that road network in Albania with all the types of roads, where the vehicles can move, is about $18.000 \mathrm{~km}$ long where $3136 \mathrm{~km}$ are national roads. Although its density is comparable with that of other neighboring countries in the region $\left(0.62 \mathrm{~km} / \mathrm{km}^{2}\right)$, the actual situation of road network is still not in good condition, with only $32 \%$ of national roads in accessable conditions.the situation get worst because of insufficient maintenance.

Table .1 Road infrastructure (National road network)

\begin{tabular}{|l||c|c|c|c|}
\hline Country & Total roads per 1000km & $\begin{array}{c}\text { National roads per } \\
1000 \mathrm{~km}\end{array}$ & $\begin{array}{c}\% \text { of paved } \\
\text { roads }\end{array}$ & Density in $\mathrm{km} / \mathrm{km}^{2}$ \\
\hline Albania & 18 & 3.136 & 12.4 & 0.62 \\
\hline Macedonia & 8.634 & - & 63.8 & 0.34 \\
\hline Serbia/Montenegro & 48.603 & 18.99 & 62.3 & 0.49 \\
\hline Greece & 117 & 40.4 & 91.8 & 0.89 \\
\hline
\end{tabular}

Source : MPPTT, 2009 
Figure1 National road network to the region

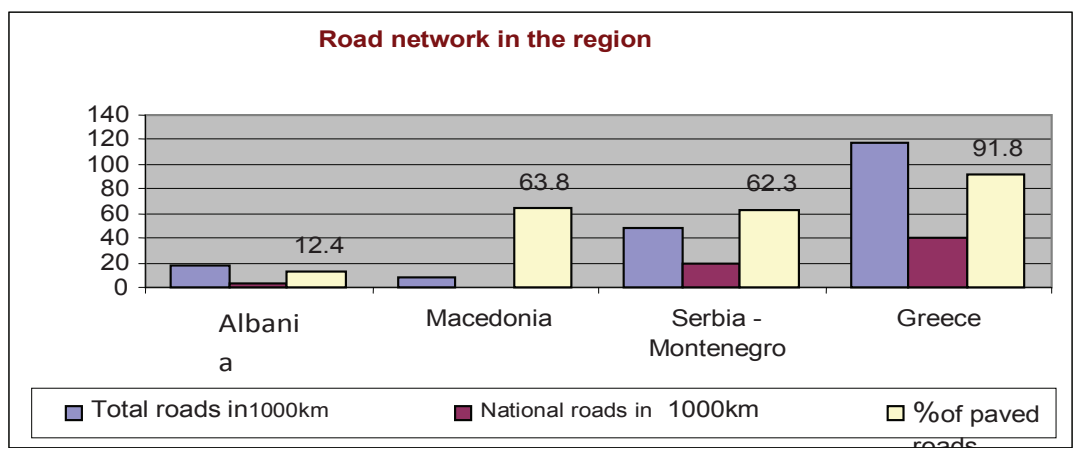

Source: MPPTT, 2009

Another land transportation mode that is also important for movement of people and goods is rail transport, which in Albania has not gained the necessary attention by policy makers and actually is in very bad conditions. This can be noticed by the comparative analysis made with other countries of the region (Figure 2), according to the total length of rail lines, and also by making an analysis of investments realized in Albania related to rail transport over last 10 years (Figure 3). Only in case of rail transport is noticed a total missing of foreign financial resources in increasing and improving of rail transport network. The main reason for this is that this network is almost damaged and in fact is not of considerable importance for movement of people and goods in Albanian territory.

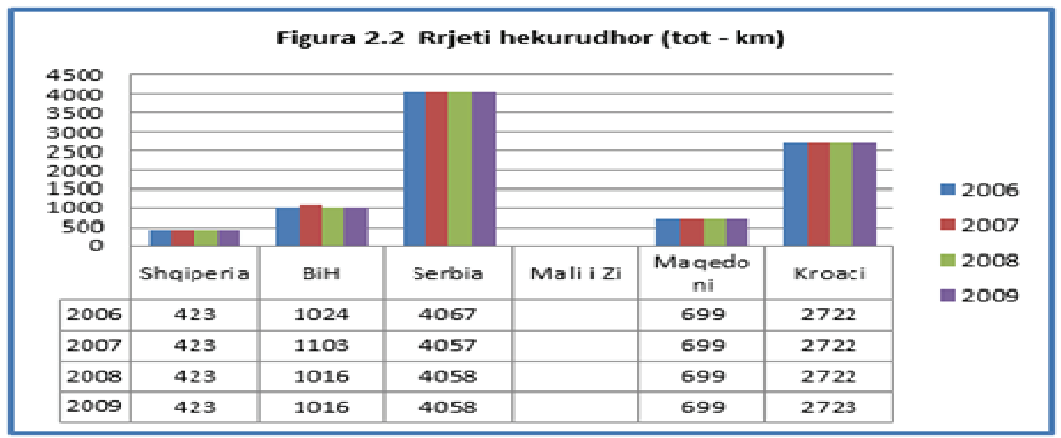

Source:http://data.worldbank.org/indicator/IS.RRS.TOTL.KM/countries (2010)

Figure 3. Investments realized in rail transport infrastructure

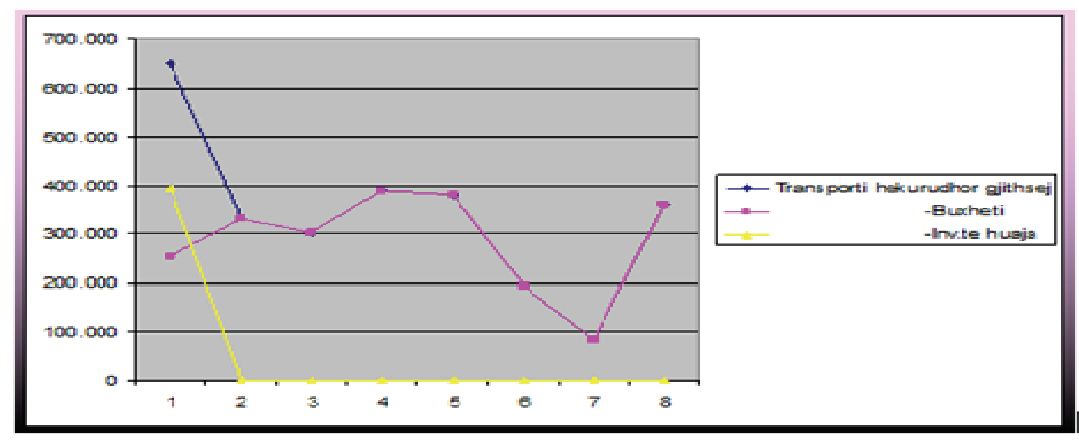

Source: MPPTT, 2009 
A completely different situation is noticed in the case of road transportation infrastructure, where the level of investmes is in increaing trend, especially from 2005 and so on. Also, looking at the figure below it is evident that a very high level of foreign investments is focused on road transportation infrastructure during last years in comparison to the level of investments in this kind of infrastructure financed by state budget.

Figure.4 Investments realized in road transport infrastructure

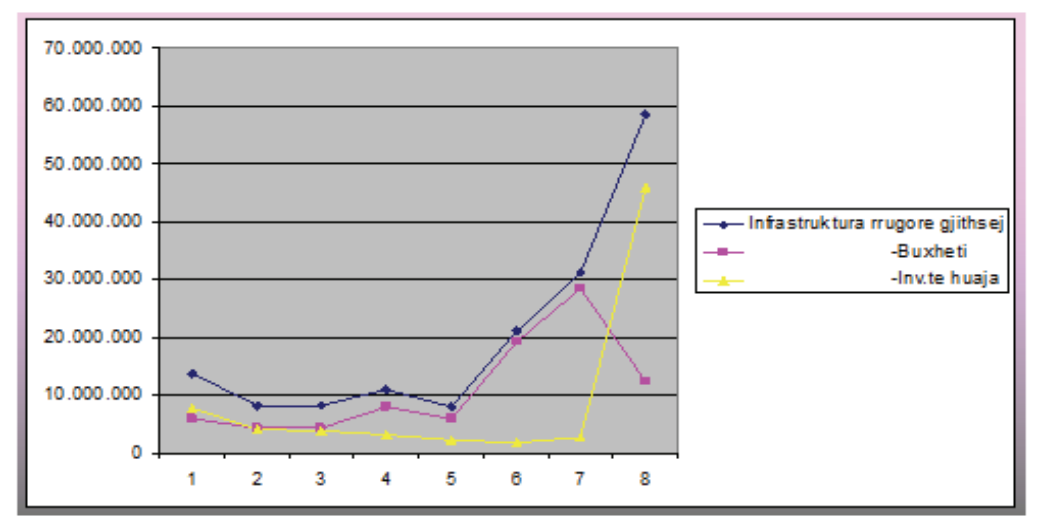

Source: MPPTT, 2009

\section{Transportation planning problems in Albania}

The importance of planning in transportation is obvious. Ineffective planning, with regard to its concepts and instruments does not reduce the problems at all.

The most striking fact of the last 10 years of the transportation field is that the majority of highways built in recent years were built by spending more than being planned. On the other hand, at the stage where decisions were being made for these motorways, "National Transportation Plan" was in operation and it was paid a lot of attention in building secondary roads, despite the fact that in Albania primary roads are not yet in good conditions, as seen in the section above. So, the sustainable development in the transportation sector in Albania has faced problems related to the planning process. Some of the examples are unplanned developments resulting from the lack of or a misunderstanding of the planning concept. The others are developments against plans under operation. The lack of a planning tradition causes diffidence against the planning concept and reduces the effects of the efforts made in favor of planned development.

\section{Policy objectives}

The challenge of developing transport policies for sustainable development is to orient the sector towards a compromise that maximizes the economic and social benefits of transport and minimizes associated environmental, social and economic costs. Many of the measures required to achieve this balance are not new, the main difficulty is effective implementation.

\section{Efficiency}

The most efficient approach to achieving sustainable development of the transport sector requires a combination of regulatory instruments (particularly for vehicle emissions) and restructuring of charges and taxes on the basis of marginal costs to provide incentives to reduce external costs to optimal levels. It often also requires improvement of the quality of transport, especially rail services (ensuring reliability and complete logistic services) and promotion of inter - modal services. Failure to structure charges efficiently will make the use of other tools much less cost effective.

Initially the structure of charges is more important than the precise level. It should be noted that efficient prices do not generally coincide with coverage of total infrastructure costs. In this context it has to be acknowledged that efficiency 
is not the only political consideration in setting the level of charges, and budgetary pressures at times result in increasing charges above marginal social cost levels.

\section{Decision making}

Despite the major environmental costs of transport, the benefits are large and the real issue is in making decisions that achieve the greatest benefits while minimizing the costs. How this balance is reached in making decisions on transport projects, and also policies, is critical to making the transport system sustainable in practice.

\section{Evaluating transport policies and projects}

Recent work underlines the importance of good cost benefit analysis (CBA) to making sustainable investment and policy decisions. It also provides a framework for arriving at reliable results in the face of market failures that are widespread in transport, overcoming weaknesses in traditional CBA that has undermined its use in many countries in which additional analysis is appropriate according to the degree to which there is a distortion in a) transport prices and b) the prices of products on the market:

- Where distortion are minor, good traditional CBA is adequate to capture all economic benefits flowing from the decision to invest. There are no significant additional economic benefits (e.g. from regional development) beyond those captured by the analysis.

- Where prices are distorted there will be additional benefits and costs to consider.

- But where transport prices are distorted, it will be appropriate to correct transport prices rather than shape investment decisions on the basis of inefficient pricing.

\section{Conclusions and Recommendations}

Sustainable development in the transportation sector in Albania has faced problems related to the planning process. Some of the examples are unplanned developments resulting from the lack of or a misunderstanding of the planning concept. The others are developments against plans under operation. The lack of a planning tradition causes diffidence against the planning concept and reduces the effects of the efforts made in favor of planned development.

The challenge of developing transport policies for sustainable development is to orient the sector towards a compromise that maximizes the economic and social benefits of transport and minimizes associated environmental, social and economic costs. Many of the measures required to achieve this balance are not new, the main difficulty is effective implementation.

Despite the major environmental costs of transport, the benefits are large and the real issue is in making decisions that achieve the greatest benefits while minimizing the costs. How this balance is reached in making decisions on transport projects, and also policies, is critical to making the transport system sustainable in practice.

\section{References}

Alexander, I. \& Estache, A. (2000). Infrastructure restructuring and regulation: Building a base for sustainable growth. World Bank Policy Research Working Paper No. 2415

MPPTT, 2007 Strategjia sektoriale e transportit 2007 - 2013

MPPTT, 2009 Plani Kombwtar i Transportit

Kirkpatrick, C., Parker, D., \& Zhang, Y. F. (2006) Foreign direct investment in Infrastructure in developing countries: Does regulation make a difference? Transnational Corporations, 15(1), 143-172

Semmler, W., Greiner. A., Diallo, B., Rezai, A. \& Rajaram, A. (2007) Fiscal Policy, Public Expenditure composition, and growth theory and empirics. World Bank Policy Research Working Paper 4405.

World Bank. (2004). Averting an infrastructure crisis: A framework for policy and action. Washington DC: World Bank 